\title{
Simulation framework for connected vehicles: a scoping
}

\section{review [version 1; peer review: 2 approved with reservations]}

\author{
Siti Fatimah Abdul Razak (D1), Sumendra Yogarayan (iD), Afizan Azman2, \\ Mohd Fikri Azli Abdullah, Anang Hudaya Muhamad Amin (1D), Mazzar Salleh4 \\ ${ }^{1}$ Faculty of Information Science and Technology, Multimedia University, Ayer Keroh, Melaka, 75450, Malaysia \\ ${ }^{2}$ Kolej Universiti Islam Melaka, Kuala Sg Baru, Melaka, Malaysia \\ ${ }^{3}$ Faculty of Computer, Information Science and Applied Media, Higher Colleges of Technology, Dubai, United Arab Emirates \\ ${ }^{4}$ Rolls-Royce, Derby, England, UK
}

V1 First published: 09 Dec 2021, 10:1265
https://doi.org/10.12688/f1000research.73398.1

Latest published: 16 Feb 2023, 10:1265

https://doi.org/10.12688/f1000research.73398.2

\section{Abstract}

Background: V2V (Vehicle-to-Vehicle) is a booming research field with a diverse set of services and applications. Most researchers rely on vehicular simulation tools to model traffic and road conditions and evaluate the performance of network protocols. We conducted a scoping review to consider simulators that have been reported in the literature based on successful implementation of V2V systems, tutorials, documentation, examples, and/or discussion groups. Methods: Simulators that have limited information were not included. The selected simulators are described individually and compared based on their requirements and features, i.e., origin, traffic model, scalability, and traffic features. This scoping review was reported according to the Preferred Reporting Items for Systematic Reviews and Meta-Analyses extension for Scoping Reviews (PRISMA-ScR). The review considered only research published in English (in journals and conference papers) completed after 2015. Further, three reviewers initiated the data extraction phase to retrieve information from the published papers.

Results: Most simulators can simulate system behaviour by modelling the events according to pre-defined scenarios. However, the main challenge faced is integrating the three components to simulate a road environment in either microscopic, macroscopic or mesoscopic models. These components include mobility generators, VANET simulators and network simulators. These simulators require the integration and synchronisation of the transportation domain and the communication domain. Simulation modelling can be run using a different types of simulators that are cost-effective and scalable for evaluating the performance of V2V systems in urban environments. In addition, we also considered the ability of the vehicular simulation tools to support wireless sensors.

Conclusions: The outcome of this study may reduce the time required for other researchers to work on other applications involving V2V
Open Peer Review

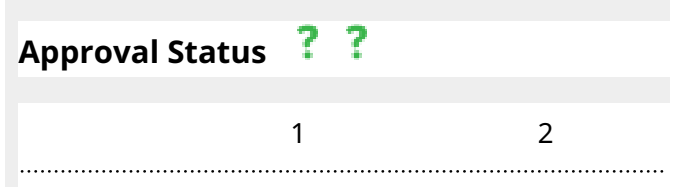

version 2

(revision)

16 Feb 2023

version 1

09 Dec 2021

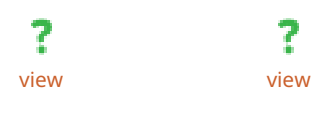

1. Lionel Nkenyereye (D), Sejong University,

Seoul, South Korea

2. Mahmoud Zaki Iskandarani (iD), Al-Ahliyya

Amman University, Amman, Jordan

Any reports and responses or comments on the article can be found at the end of the article. 
systems and as a reference for the study and development of new traffic simulators.

Keywords

V2V, network simulator, mobility generator, simulations, connected vehicles, microscopic models

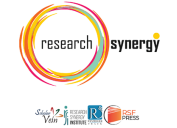

This article is included in the Research Synergy

sing

Foundation gateway.

Corresponding author: Siti Fatimah Abdul Razak (fatimah.razak@mmu.edu.my)

Author roles: Abdul Razak SF: Conceptualization, Data Curation, Investigation, Methodology, Writing - Original Draft Preparation, Writing - Review \& Editing; Yogarayan S: Conceptualization, Data Curation, Investigation, Validation, Writing - Review \& Editing; Azman A: Investigation, Project Administration, Validation; Abdullah MFA: Investigation, Visualization, Writing - Review \& Editing; Muhamad Amin AH: Methodology, Validation; Salleh M: Validation, Visualization, Writing - Review \& Editing

Competing interests: No competing interests were disclosed.

Grant information: The author(s) declared that no grants were involved in supporting this work.

Copyright: ( 2021 Abdul Razak SF et al. This is an open access article distributed under the terms of the Creative Commons Attribution License, which permits unrestricted use, distribution, and reproduction in any medium, provided the original work is properly cited.

How to cite this article: Abdul Razak SF, Yogarayan S, Azman A et al. Simulation framework for connected vehicles: a scoping review [version 1; peer review: 2 approved with reservations] F1000Research 2021, 10:1265 https://doi.org/10.12688/f1000research.73398.1

First published: 09 Dec 2021, 10:1265 https://doi.org/10.12688/f1000research.73398.1 


\section{Introduction}

In recent decades, a significant increase in vehicle use has increased traffic congestion and fatalities ${ }^{1}$. According to the World Health Organization, 1.25 million people are killed and severely injured involving vehicle accidents ${ }^{2}$. Hence, connected vehicle technology responds to this constraint, aiming to leverage inter-vehicle communication to produce safe, user-friendly, and fuel-efficient vehicle assistive technologies ${ }^{3,4}$. One of the main aspects of connected vehicle research is to optimise traffic flow through the exchange of information ${ }^{5}$. This communication can be sorted in terms of vehicle $(\mathrm{V} 2 \mathrm{~V})$, infrastructure (V2I), a pedestrian (V2P), and network $(\mathrm{V} 2 \mathrm{~N})^{6,7}$. The exchange of information, collectively known as V2X communications, could assist drivers in preventing accidents by providing warnings of danger invisible to drivers and other sensors (e.g. collision avoidance, lane departure warning and speed limit alert $)^{8,9}$.

Nevertheless, the adoption of connected vehicle technology poses a range of challenges, particularly in urban environments. It is challenging to analyse the effectiveness of the application of connected vehicles under traffic conditions ${ }^{10-12}$. As such, simulations using traffic and network simulators as well as mobility generators are viable alternatives to modelling and determining the effectiveness of such deployments in the real world ${ }^{13,14}$, as it provides an affordable and scalable method for analysing model compliance in various contexts and parameters.

Traffic simulations are categorised by level of detail into three separate categories ${ }^{15}$. First, the most precise information on each vehicle in the system is microscopic simulations ${ }^{16}$. Second, mesoscopic simulations exploit aggregate velocity-density functions to represent their behaviour and view traffic as a continuous stream of vehicles ${ }^{17}$. Finally, macroscopic simulation is the large-scale traffic model, which focuses on combined traffic status ${ }^{18}$. Microscopic simulations provide the highest degree of detail for modelling, although they are the slowest to execute $^{19,20}$.

In addition, mobility generators are a possible option for modelling vehicle elements such as traffic, temporal and spatial mobility, and generating mobility traces ${ }^{21,22}$. These traces are then uploaded to a network simulator, which mimics vehicle-to-vehicle communication. Furthermore, these traces can be generated by observing real-world vehicles on the road and then used in network simulations ${ }^{23,24}$. The effect of network parameter modifications on traffic mobility is a strategic objective simulation ${ }^{25}$. It is also restricted to the use of the trace controlled by the mobility model. Another option is to use a simulator that directly integrates the mobility framework.

For Vehicular Adhoc Networks (VANET), it is necessary to rely on network protocols to assess their performance ${ }^{22,23}$, given that actual experiments are not possible. Over the last decade, efforts have been made to produce a full transport simulator for VANET solutions, including a wireless network simulator for modelling and evaluation ${ }^{24,25}$. A wide range of simulators can be used for VANET simulation modelling, both commercial and open source. Older simulators provide a network simulator to communicate with stationary mobility models. Many researchers have examined various mobility models with simulation tools for several contexts. Such simulator tools are not yet well explored since many researchers base their simulations depending on their use case settings. Thus, this motivates the identification of different simulators do not yet exist. Therefore, this study conducted a systematic scoping review to identify the applicability and availability of existing mobility generators, network simulators, and combination simulators.

\section{Methods}

A popular approach to synthesize research evidence which have no definitive procedure established is known as a scoping review. To conduct the review process, we adopted the PRISMA Extension for a Scoping Review ${ }^{26}$. The process involves determining the subjective and objective outcomes, identifying and selecting relevant studies, organising and summarising the findings, and reporting the outcomes (see Figure 1). Review questions were developed as follows:

1. What are available mobility generators which are currently active in vehicle simulations?

2. What is the criteria of network simulators commonly used in vehicle simulation active development?

3. Which mobility networks and network simulators have been integrated to study vehicle communication protocols?

\section{Search, sources and inclusion criteria}

Relevant studies were identified from IEEE and ScienceDirect, only including journal and conference papers with a published status. All searches were initiated in November 2019, and articles published in English starting from 2015 were considered for evaluation as our analysis of the literature shows that it is a relatively new but rapidly growing field of academic endeavour.

Controlled phrases and free-text word phrases related to vehicular communications that investigated $\mathrm{V} 2 \mathrm{~V}$ safety applications, vehicle network performance, driver behaviour, vehicle simulation tools, and VANET were considered for inclusion (see Box 1).

Mendeley was used to import the search results (www.mendeley.com) and remove duplicate articles.

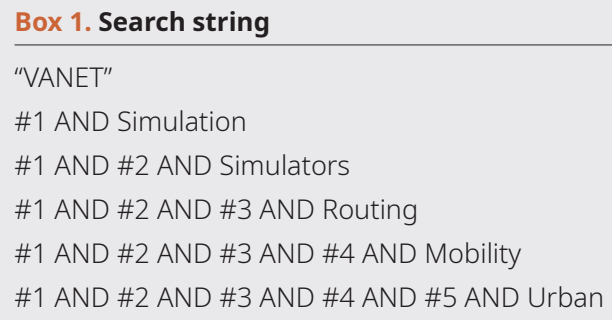

\section{Screening}

Once duplicate articles had been removed, further screening was performed at the title or abstract level based on the inclusion criteria. In addition, related technical reports were also 


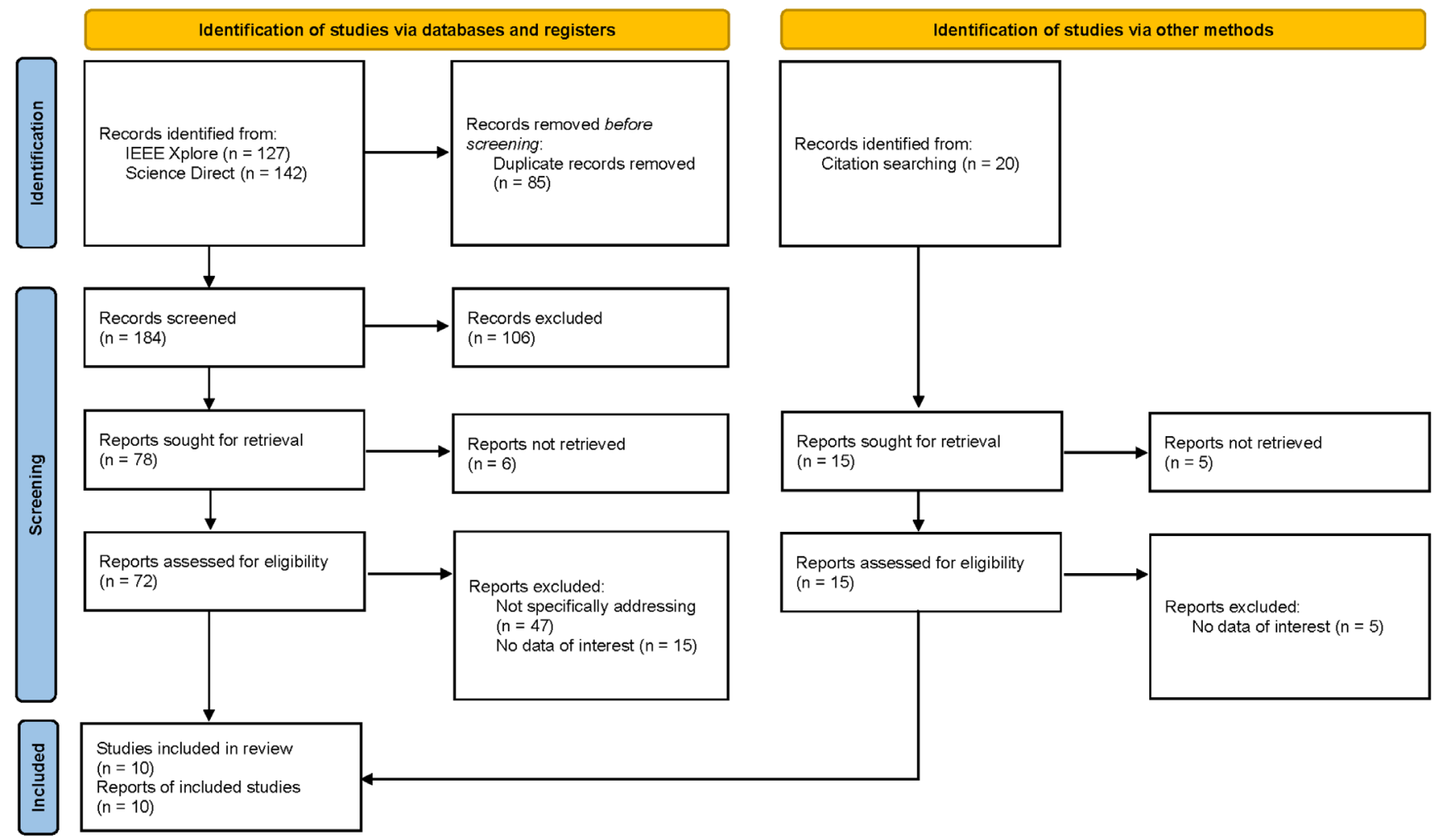

Figure 1. PRISMA Flow Diagram.

included from Google Scholar. For confirmation, filtering (e.g. possible synonyms or other related terms) was also done at the full-text level afterwards. Citations of the articles included were searched for other relevant articles.

To facilitate the screening task, we imported the bibliographic citation file in RIS format from Mendeley into Rayyan (https://www.rayyan.ai/). Three reviewers (S.Y., A.A., and M.F.A.A.) were involved in the screening process to minimise bias and ensure the consistency of the selected articles. The first screening process ended in April 2020 and was later updated in January 2021.

\section{Data extraction and analysis}

All reviewers reviewed the same article and reports during the data extraction phase before collating their findings in an MS Excel spreadsheet. Data related to objective outcomes were collected from each included article wherever available, including year, type of traffic model, architecture and simulation language, type of network simulator, type of mobility generator, implementation or experimentation scenario and type of license. The spreadsheets were compared to ensure consistent data extraction by all reviewers. The contribution of the studies was further analysed based on descriptions provided in the publications paper to consider in our scoping review. In March 2021, the data extraction and analysis were finalised by consensus among the reviewers.

\section{Results}

A total of 269 publications were found initially. After removing duplicates, a total of 184 titles and abstracts were screened, from which 72 publications were subjected to full-text review after excluding those not of interest to this study. In total, ten studies and reports fulfilled the criteria for inclusion and were included in the analysis (see Figure 1).

We found that open-source mobility and network simulators were popular among researchers. Microscopic models were preferable for research related to vehicular communications since the simulations provide the most precise information of each vehicle or mobile node and the highest degree of detail for modelling compared to macroscopic and mesoscopic models. Common network simulators were NS-2, Ns-3 and OMNeT++. However, not all mobility simulators supported active development, which is important in current active research domains such as vehicular communications. The summary of mobility generators and network simulators found are in Table 1 and Table 2, respectively. A list of all ten studies can be found in Table 3 . 
Table 1. Mobility generators.

\begin{tabular}{|c|c|c|c|c|c|c|c|}
\hline Reference(s) & $\begin{array}{l}\text { Name of } \\
\text { mobility } \\
\text { generator }\end{array}$ & $\begin{array}{c}\text { Active } \\
\text { development }\end{array}$ & Release & License & Map & Traffic model & Network simulator \\
\hline $27-29$ & SUMO & Y & 2021 & Open Source & $\begin{array}{l}\text { Real and User } \\
\text { Defined }\end{array}$ & $\begin{array}{l}\text { Microscopic } \\
\text { Mesoscopic }\end{array}$ & NS-2, NS-3, OMNeT++ \\
\hline $30-32$ & MATSim & Y & 2021 & Open Source & $\begin{array}{l}\text { Real and User } \\
\text { Defined }\end{array}$ & Microscopic & N/A \\
\hline 33 & DTALite & Y & 2021 & Open Source & Real & Mesoscopic & $\mathrm{N} / \mathrm{A}$ \\
\hline 34,35 & SMARTS & Y & 2020 & Open Source & $\begin{array}{l}\text { Real and User } \\
\text { Defined }\end{array}$ & Microscopic & N/A \\
\hline $21,36,37$ & PARAMICS & Y & 2020 & Commercial & $\begin{array}{l}\text { Real and User } \\
\text { Defined }\end{array}$ & Microscopic & NS-2, OMNeT++ \\
\hline 31,37 & MovSim & Y & 2018 & Open Source & Built-In & Microscopic & N/A \\
\hline $21,38,39$ & VISSIM & Y & 2016 & Commercial & $\begin{array}{l}\text { Real and User } \\
\text { Defined }\end{array}$ & $\begin{array}{l}\text { Microscopic } \\
\text { Mesoscopic }\end{array}$ & NS-2, QualNet \\
\hline 40 & VNEtIntSim & $\mathrm{N}$ & 2015 & Open Source & $\begin{array}{l}\text { Real and User } \\
\text { Defined }\end{array}$ & Microscopic & Integration OPNET \\
\hline 37 & Traffisim & $\mathrm{N}$ & 2014 & Open Source & $\begin{array}{l}\text { Real and User } \\
\text { Defined }\end{array}$ & Microscopic & N/A \\
\hline 41 & CityMob & N & 2009 & Open Source & Built-In & $\begin{array}{l}\text { Microscopic } \\
\text { Macroscopic }\end{array}$ & NS-2 \\
\hline 41 & FreeSim & N & 2008 & Open Source & Real & $\begin{array}{l}\text { Microscopic } \\
\text { Macroscopic }\end{array}$ & N/A \\
\hline 41 & STRAW & N & 2007 & Open Source & Built-In & Microscopic & NS-2, SWANS \\
\hline 41 & $\begin{array}{l}\text { Vanet- } \\
\text { MobiSim }\end{array}$ & $N$ & 2007 & Open Source & $\begin{array}{l}\text { Real and User } \\
\text { Defined }\end{array}$ & Microscopic & $\begin{array}{c}\text { NS-2, QualNEt, } \\
\text { OMNeT++, GloMoSim }\end{array}$ \\
\hline
\end{tabular}

$\mathrm{Y}=$ Supported, $\mathrm{N}=$ Not Supported

Table 2. Network simulators.

\begin{tabular}{|c|c|c|c|c|c|c|c|}
\hline Reference(s) & $\begin{array}{l}\text { Name of network } \\
\text { simulators }\end{array}$ & $\begin{array}{c}\text { Active } \\
\text { development }\end{array}$ & Release & License & $\begin{array}{l}802.11 p \\
\text { Support }\end{array}$ & $\begin{array}{l}\text { Architecture } \\
\text { Language }\end{array}$ & $\begin{array}{l}\text { Simulation } \\
\text { Language }\end{array}$ \\
\hline 42,43 & OPNET & Y & 2021 & Commercial & Y & $\mathrm{C}++$ & $\begin{array}{l}\text { C++ } \\
\text { OTCL }\end{array}$ \\
\hline $32,42,44$ & NS-3 & Y & 2021 & Open Source & Y & $\begin{array}{c}\text { C++ } \\
\text { Python }\end{array}$ & $\begin{array}{c}\text { C++ } \\
\text { Python }\end{array}$ \\
\hline 42 & OMNeT++ & Y & 2020 & Open Source & Y & $\mathrm{C}++$ & $\mathrm{C}++$ \\
\hline 32,42 & QualNet & Y & 2019 & Commercial & Y & $\mathrm{C}++$ & $\mathrm{C}++$ \\
\hline 42,45 & NS-2 & $\mathrm{N}$ & 2011 & Open Source & Y & $\mathrm{C}++$ & $\begin{array}{l}\mathrm{C}++ \\
\mathrm{OTCL}\end{array}$ \\
\hline 32,42 & JIST/SWANS & $\mathrm{N}$ & 2005 & Open Source & N & JAVA & JAVA \\
\hline 40,45 & GloMoSim & $\mathrm{N}$ & 2000 & Open Source & $\mathrm{N}$ & C & C \\
\hline
\end{tabular}

$Y=$ Supported, $N=$ Not Supported 


\section{Table 3. Previous studies.}

\begin{tabular}{|c|c|c|c|c|c|c|}
\hline Reference & Contribution & Scenario & $\begin{array}{l}\text { Protocol } \\
\text { Used }\end{array}$ & $\begin{array}{l}\text { Mobility } \\
\text { Simulator }\end{array}$ & $\begin{array}{l}\text { Network } \\
\text { Simulator }\end{array}$ & $\begin{array}{c}\text { Simulator and } \\
\text { Framework }\end{array}$ \\
\hline 46 & $\begin{array}{l}\text { This paper provides a comparison of three } \\
\text { routing protocols in the VANET scenario. The } \\
\text { result focuses on determining the effectiveness } \\
\text { of routing protocols for several performance } \\
\text { measures of which the vehicle is an essential } \\
\text { aspect of the evaluation. }\end{array}$ & Urban & $\begin{array}{c}\text { DSDV } \\
\text { AODV } \\
\text { DSR }\end{array}$ & $\begin{array}{l}\text { SUMO } \\
\text { MOVE }\end{array}$ & NS-2 & N/A \\
\hline 47 & $\begin{array}{l}\text { The paper provides a simulation in the VANET } \\
\text { scenario at a vast scale. The result is focused } \\
\text { on the performance of four routing protocols } \\
\text { under different checks in terms of delay, packet } \\
\text { delivery, overhead, and transmission power. }\end{array}$ & Urban & $\begin{array}{l}\text { OLSR } \\
\text { DSDV } \\
\text { AODV } \\
\text { DSR }\end{array}$ & SUMO & NS-3 & $N / A$ \\
\hline 48 & $\begin{array}{l}\text { This paper uncovers an automatic routing } \\
\text { protocol for the VANET scenario. The idea is } \\
\text { to disseminate the information provided by } \\
\text { several roadside units. There are three routing } \\
\text { protocols evaluated using several performance } \\
\text { metrics in terms of delay, number of hops, total } \\
\text { service time, and number of fragments. }\end{array}$ & Urban & $\begin{array}{c}\text { ARP GSR } \\
\text { A-STAR }\end{array}$ & SUMO & OMNeT++ & N/A \\
\hline 49 & $\begin{array}{l}\text { The paper focuses on two routing protocols } \\
\text { within the VANET scenario. The idea is to } \\
\text { ensure an optimal path from source to } \\
\text { destination under a few performance measures } \\
\text { in terms of throughput and packet delivery } \\
\text { ratio. }\end{array}$ & Generic & $\begin{array}{c}\text { DYMO } \\
\text { OLSR }\end{array}$ & N/A & QualNet & $N / A$ \\
\hline 50 & $\begin{array}{l}\text { This paper investigates DSRC } 5.9 \mathrm{GHz} \text { for the } \\
\text { V2V scenario in restricted areas. The findings } \\
\text { were reviewed using three routing protocols } \\
\text { using different performance parameters in } \\
\text { terms of delay and number of forwarding } \\
\text { nodes. }\end{array}$ & Generic & $\begin{array}{c}\text { EMDV } \\
>\text { MHVB } \\
\text { EDB }\end{array}$ & N/A & NetSim & $N / A$ \\
\hline 29 & $\begin{array}{l}\text { The paper provides an analysis of four routing } \\
\text { protocols within the VANET scenario. The } \\
\text { outcome was assessed based on a different } \\
\text { mobility model and speed and performance } \\
\text { parameters such as goodput, throughput, } \\
\text { packet receive performance and receive rate. }\end{array}$ & Urban & $\begin{array}{l}\text { OLSR } \\
\text { AODV } \\
\text { DSDV } \\
\text { DSR }\end{array}$ & SUMO & NS-3 & N/A \\
\hline 27 & $\begin{array}{l}\text { This paper provides a comparison of three } \\
\text { routing protocols for the VANET scenario. } \\
\text { The results show the performance in the } \\
\text { transmission of critical information within } \\
\text { the framework of several performance } \\
\text { assessments in terms of goodput and packet } \\
\text { delivery ratio. }\end{array}$ & Generic & $\begin{array}{l}\text { OLSR } \\
\text { AODV } \\
\text { DSDV }\end{array}$ & SUMO & NS-3 & $N / A$ \\
\hline 51 & $\begin{array}{l}\text { The paper presents a fuzzy logic method to } \\
\text { improve the routing protocol in the VANET } \\
\text { scenario. The study demonstrated the } \\
\text { simulation by considering the number of } \\
\text { vehicles, the extent of the transmission, and } \\
\text { vehicle speed movement. }\end{array}$ & $\begin{array}{l}\text { Urban } \\
\text { Generic }\end{array}$ & AODV & SUMO & OMNeT++ & $N / A$ \\
\hline 52 & $\begin{array}{l}\text { This paper uncovers a road recovery } \\
\text { mechanism in the VANET scenario. The study } \\
\text { improved the pathway to better message } \\
\text { delivery by considering mobility measures such } \\
\text { as relative speeds and relative distance. }\end{array}$ & Generic & $\begin{array}{l}\text { CLARR } \\
\text { CCBR }\end{array}$ & $N / A$ & NS-2 & $N / A$ \\
\hline 53 & $\begin{array}{l}\text { The paper examined two routing protocols } \\
\text { for better message dissemination in V } 2 \mathrm{~V} \text { and } \\
\text { V2I scenarios. The findings demonstrated } \\
\text { optimised routing under several performance } \\
\text { assessments like throughput, packet loss, } \\
\text { packet delivery report, and delay. }\end{array}$ & Urban & $\begin{array}{c}\text { AODV } \\
\text { DSR }\end{array}$ & SUMO & N/A & NetSim \\
\hline
\end{tabular}

N/A - Not Applied 


\section{Discussion}

Since this area of study is considered as a relatively new but rapidly growing field, this scoping review process only considers relevant papers published from 2015 onwards, which shows that extensive research has been conducted to create security standards for communication technologies, particularly the vehicular network. Although various simulators can be enhanced with library extensions, none of the simulators is related to security and privacy. Ultimately, researchers and professionals cannot compare their security measures to a given circumstance. For instance, ensuring the privacy of a vehicular user in a fast-moving network and disseminating messages in a secure vehicular environment. However, there is no simple practice of extending existing simulators to the desired security standard, which implies that future development research will need to be done.

In addition, the quality of a simulation depends largely on the precision of the models. The range of precision has increased dramatically recently, where several modules contain signal attenuation components, multiple antenna models, and environmental interferences. However, one continuous barrier to producing accurate simulations is the evolution of rapid prototyping and its increasing use in-vehicle networks. For example, vehicle nodes would depend on three-dimensional scenarios to communicate with other nodes. It would be crucial for current and future simulators to extend the current simulators to these new conditions.

Integration with real-time system modelling based on non-real-time events creates additional challenges. Due to resource limitations, current simulators do not correspond with the physical properties of the hardware prototype while simulating a comprehensive network with multiple vehicles. Several alternatives have been put forward to reduce the complexity that could speed the simulation. However, this approach usually does not include indirect outcomes, which could seriously impact the behaviour of real-world network components. It is, therefore, necessary to examine the interconnection between simulators and hardware devices with the security standards concerned.

\section{Conclusions}

Studies have led to the discovery of comprehensive and realistic simulation tools due to the increasing popularity and interest for the future transportation system. This work has examined the current availability of simulators. Although several simulators have many features, it is worth exploring further the improvement of the simulators for specific scenarios.

\section{Data availability}

\section{Underlying data}

All data underlying the results are available as part of the article and no additional source data are required.

\section{Reporting guidelines}

Zenodo: PRISMA-ScR checklist for 'Simulation framework for connected vehicles: a systematic review', https://doi.org/10.5281/ zenodo. $5637802^{54}$

Data are available under the terms of the Creative Commons Attribution 4.0 International license (CC-BY 4.0).
1. Retallack $A E$, Ostendorf B: Current Understanding of the Effects of Congestion on Traffic Accidents. Int J Environ Res Public Health. 2019; 16(18): 3400.

PubMed Abstract | Publisher Full Text | Free Full Text

2. Karim F, Albrka Ali SI: Evaluation of Most Influential Factors Affecting Road Traffic Accidents in Sidon, Lebanon. Jurnal Kejuruteraan. 2020; 32(3): 467-473. Reference Source

3. Ukkusuri S, Sagir F, Mahajan N, et al:: Strategic and Tactical Guidance for the Connected and Autonomous Vehicle Future. West Lafayette, IN Aug. 2019. Publisher Full Text

4. Feng $\mathrm{Y}$, Zheng J, Liu HX: Real-time detector-free adaptive signal control with low penetration of connected vehicles. Transp Res Record. 2018; 2672(18): 35-44. Publisher Full Text

5. Shladover SE: Connected and automated vehicle systems: Introduction and overview. J Intell Transport S: Technology, Planning, and Operations. 2018; 22(3): 190-200.

Publisher Full Text

6. Choi YJ, Hur J, Jeong HY, et al.: Special Issue on V2X Communications and Networks. J Commun Netw. 2017; 19(3): 205-206. Publisher Full Text

7. Domínguez JML, Mateo Sanguino TJ: Review on V2X, I2X, and P2X Communications and Their Applications: A Comprehensive Analysis ove Time. Sensors (Basel). 2019; 19(12): 2756.

PubMed Abstract | Publisher Full Text | Free Full Text

8. Khan UA, Lee SS: Distance-based resource allocation for vehicle-to-
Pedestrian safety communication. Electronics (Switzerland). 2020; 9(10): 1-17. Publisher Full Text

9. Arena F, Pau G: An overview of vehicular communications. Future Internet 2019; 11(2): 27

Publisher Full Text

10. Bezai NE, Medjdoub B, Al-Habaibeh A, et al.: Future cities and autonomous vehicles: analysis of the barriers to full adoption. Energy and Built Environment. 2021; 2(1): 65-81. Publisher Full Text

11. Gavanas N: Autonomous Road Vehicles: Challenges for Urban Planning in European Cities. Urban Sci. 2019; 3(2): 61 Publisher Full Text

12. Wen L, Kenworthy J, Guo X, et al: Solving Traffic Congestion through Street Renaissance: A Perspective from Dense Asian Cities. Urban Sci. 2019; 3(1): 18. Publisher Full Text

13. Durán JM: What is a Simulation Model? Mind Mach. 2020; 30(3): 301-323. Publisher Full Text

14. Gray J, Rumpe B: Models in simulation. Softw Syst Model. 2016; 15(3): 605-607. Springer Verlag. Publisher Full Text

15. Kim J, Kim JH, Lee G, et al:: Microscopic Traffic Simulation Calibration Level for Reliable Estimation of Vehicle Emissions. J Adv Transport. 2020; 2020 : 4038305. Publisher Full Text

16. Zehe D, Grotzky D, Aydt $H$, et al.: Traffic simulation performance 
optimisation through multi-resolution modeling of road segments. In SIGSIM-PADS 2015 - Proceedings of the 3rd ACM Conference on SIGSIM-Principles of Advanced Discrete Simulation. 2015; 281-288.

Publisher Full Text

17. Yuan H, Li G: A Survey of Traffic Prediction: from Spatio-Temporal Data to Intelligent Transportation. Data Sci Eng. Springer Science and Business Media Deutschland GmbH. 2021; 6(1): 63-85.

Publisher Full Text

18. Grzybek A, Danoy G, Bouvry P: Generation of realistic traces for vehicular mobility simulations. In DIVANet' 12 - Proceedings of the ACM Workshop on Design and Analysis of Intelligent Vehicular Networks and Applications. 2012; 131-138. Publisher Full Text

19. Rivoirard L, Berbineau M, Wahl M, et al.: Using Real-World Car Traffic Dataset in Vehicular Ad Hoc Network Performance Evaluation. 2016. Publisher Full Text

20. Lee $\mathrm{CH}$, Lim KG, Chua BL, et al.: Progressing toward urban topology and mobility trace for Vehicular Ad Hoc Network (VANET). In ICOS 2016 - 2016 IEEE Conference on Open Systems. 2017; 120-125. Publisher Full Text

21. Matcha BN, Namasivayam SN, Hosseini Fouladi M, et al.: Simulation Strategies for Mixed Traffic Conditions: A Review of Car-Following Models and Simulation Frameworks. Journal of Engineering (United Kingdom). Hindawi Limited. 2020. Publisher Full Text

22. Yasser A, Zorkany M, Abdel Kader N: VANET routing protocol for V2V implementation: A suitable solution for developing countries. Cogent Eng. 2017; 4(1): 1362802 Publisher Full Text

23. Tripp-Barba C, Zaldívar-Colado A, Urquiza-Aguiar L, et al.: Survey on routing protocols for vehicular ad Hoc networks based on multimetrics. Electronics (Switzerland). MDPI AG. 2019; 8(10): 1177. Publisher Full Text

24. Kim J, Sridhara V, Bohacek S: Realistic mobility simulation of urban mesh networks. Ad Hoc Networks. 2009; 7(2): 411-430. Publisher Full Text

25. Kang S, Aldwairi M, il Kim K: A survey on network simulators in threedimensional wireless ad hoc and sensor networks. Int J Distrib Sens N. 2016; 12: 10. Publisher Full Text

26. Tricco AC, Lillie $E$, Zarin W, et al.: PRISMA extension for scoping reviews (PRISMA-ScR): Checklist and explanation. Ann Intern Med. American College of Physicians. 2018; 169(7): 467-473. PubMed Abstract | Publisher Full Text

27. Shaban AM, Kurnaz S, Shantaf AM: Evaluation DSDV, AODV and OLSR routing protocols in real live by using SUMO with NS3 simulation in VANET. In $2 n d$ International Congress on Human-Computer Interaction, Optimisation and Robotic Applications. 2020; 1-5 Publisher Full Text

28. Ma X, Hu X, Weber T, et al.: Evaluation of accuracy of traffic flow generation in SUMO. Appl Sci. 2021; 11(6): 2584 Publisher Full Text

29. Aji Pratama R, Rosselina L, Sulistyowati D, et al.: Performance Evaluation on VANET Routing Protocols in the Way Road of Central Jakarta using NS 3 and SUMO. In 2020 International Seminar on Application for Technology of Information and Communication. 2020; 1-6. Publisher Full Text

30. Horni A, Nagel K, Axhausen KW: The multi-agent transport simulation MATSim. London: Ubiquity Press Ltd, Accessed: Aug. 15, 2021. Publisher Full Text

31. Nguyen J, Powers ST, Urquhart N, et al.: An Overview of Agent-based Traffic Simulators. 2021 Reference Source

32. Campanile L, Gribaudo $\mathrm{M}$, Iacono $\mathrm{M}$, et al.: Computer network simulation with ns-3: A systematic literature review. Electronics. 2020; 9(2): 272. Publisher Full Text

33. Zhou X, Taylor J, Pratico F: DTAlite: A queue-based mesoscopic traffic simulator for fast model evaluation and calibration. Cogent Eng. 2014; 1(1): 961345 .

Publisher Full Text

34. Ramamohanarao K, Xie H, Kulik L, et al.: SMARTS: Scalable microscopic adaptive road traffic simulator. ACM Trans Intell Syst Technol. 2016; 8(2): 1-22. Publisher Full Text
35. Xie H, Tanin E, Ramamohanarao K, et al.: Generating Traffic Data for Any City using SMARTS Simulator. SIGSPATIAL Special. 2019; 11(1): 22-28. Publisher Full Text

36. Reza I, Ratrout NT, Rahman SM: Calibration protocol for PARAMICS microscopic traffic simulation model: Application of neuro-fuzzy approach. Canadian Journal of Civil Engineering. 2016; 43(4): 361-368. Publisher Full Text

37. Kumar P, Shukla S: A Survey of Simulation Tools for VANET. Journal of Analysis and Computation (JAC). 2019; XII(I): 1-12. Reference Source

38. Zeidler V, Buck SH, Vortisch P: Simulation of Autonomous Vehicles Based on Wiedemann's Car Following Model in PTV Vissim. In Proceedings of the 2019 98th Annual Meeting of the Transportation Research Board (TRB). 2019; 13-17.

39. Wu J, Radwan E, Abou-Senna H: Determination if VISSIM and SSAM could estimate pedestrian-vehicle conflicts at signalized intersections. Journal of Transportation Safety and Security. 2018; 10(6): 572-585. Publisher Full Text

40. Sharma R, Vashisht $\mathrm{V}$, Singh U: Modelling and simulation frameworks for wireless sensor networks: A comparative study. IET Wireless Sensor Systems. 2020; 10(5): 236-241.

Publisher Full Text

41. Weber JS, Neves M, Ferreto T: VANET simulators: an updated review. Journal of the Brazilian Computer Society. 2021; 27(1).

Publisher Full Text

42. Toor AS, Jain AK: A survey on wireless network simulators. Bulletin of Electrical Engineering and Informatics. 2017; 6(1): 62-69. Publisher Full Text

43. Xie D, Li J, Gao H: Comparison and Analysis of Simulation methods for TSN Performance. In IOP Conference Series: Materials Science and Engineering. 2020; 768(5). Publisher Full Text

44. Bouras C, Gkamas A, Aniceto S, et al.: Comparison of LoRa Simulation Environments. In International Conference on Broadband and Wireless Computing, Communication and Applications. 2019; 374-385. Publisher Full Text

45. Zarrad A, Alsmadi I: Evaluating network test scenarios for network simulators systems. Int J Distrib Sens N. 2017; 13(10): 1-17. Publisher Full Text

46. Mahdi HF, Abood MS, Hamdi MM: Performance evaluation for vehicular ad-hoc networks based routing protocols. Bulletin of Electrical Engineering and Informatics. 2021; 10(2): 1080-1091. Publisher Full Text

47. Rajhi M, Madkhali H, Daghriri I: Comparison and Analysis Performance in Topology-Based Routing Protocols in Vehicular Ad-hoc Network (VANET). In 2021 IEEE 11th Annual Computing and Communication Workshop and Conference, CCWC 2021. 2021; 1139-1146. Publisher Full Text

48. Senapati BR, Khilar PM, Swain RR: Fire Controlling Under Uncertainty in Urban Region Using Smart Vehicular Ad hoc Network. Wirel Pers Commun. 2021; 116(3): 2049-2069.

Publisher Full Text

49. Abdulhafidh Dael F, Yavuz U, Jabbar WA: Performance Evaluation of DYMO and OLSRv2 Routing Protocols in VANET. International Journal of Integrated Engineering. 2020; 12(1): 50-58. Publisher Full Text

50. Chehri A, Chehri H, Hakim N, et al.: Realistic 5.9 GHz DSRC Vehicle-to-Vehicle Wireless Communication Protocols for Cooperative Collision Warning in Underground Mining. Smart Innovation, Systems and Technologies. 2020; 185: 133-141. Publisher Full Text

51. Fahad TO, Ali AA: Compressed fuzzy logic based multi-criteria AODV routing in VANET environment. International Journal of Electrical and Computer Engineering (IJECE). 2019; 9(1): 397. Publisher Full Text

52. Shafi S, Venkata Ratnam D: A Cross Layer Cluster Based Routing Approach for Efficient Multimedia Data Dissemination with Improved Reliability in VANETs. Wireless Pers Commun. 2019; 107(4): 2173-2190. Publisher Full Text

53. Malik S, Sahu PK: A comparative study on routing protocols for VANETs. Heliyon. 2019; 5(8): e02340. PubMed Abstract | Publisher Full Text | Free Full Text

54. Abdul Razak SFB, Yogarayan S, Azman A, et al.: V2V simulators. Zenodo. 2021. http://www.doi.org/10.5281/zenodo.5637802 


\section{Open Peer Review}

\section{Current Peer Review Status: ? ?}

\section{Version 1}

Reviewer Report 04 January 2023

https://doi.org/10.5256/f1000research.77046.r158671

(C) 2023 Iskandarani M. This is an open access peer review report distributed under the terms of the Creative Commons Attribution License, which permits unrestricted use, distribution, and reproduction in any medium, provided the original work is properly cited.

\section{Mahmoud Zaki Iskandarani}

Al-Ahliyya Amman University, Amman, Jordan

The article attempts to produce a guidance into the most appropriate simulators for $\mathrm{V} 2 \mathrm{~V}$, and in general V2X communications. This effort is a good effort and in the right direction in terms of what is witnessed of V2X developments under cooperative driving. However, the authors can benefit from the following comments:

1. Assigning the most appropriate simulator for a V2V or V2X application with in depth correlative analysis linked to different scenarios and protocols.

2. Comparative analysis of the used simulators per specific published article or group of articles sharing common objective, and the extent of benefit and development achieved using such simulator.

3. More detailed discussion and more comprehensive conclusion and recommendation will greatly improve the article.

Are the rationale for, and objectives of, the Systematic Review clearly stated? Yes

Are sufficient details of the methods and analysis provided to allow replication by others? Yes

Is the statistical analysis and its interpretation appropriate?

Partly

Are the conclusions drawn adequately supported by the results presented in the review? Partly

Competing Interests: No competing interests were disclosed. 
Reviewer Expertise: Intelligent Transportation Systems, Artificial Intelligence, Mobile and wireless Communication, Sensors and systems.

\section{I confirm that I have read this submission and believe that I have an appropriate level of expertise to confirm that it is of an acceptable scientific standard, however I have significant reservations, as outlined above.}

Author Response 26 Jan 2023

Siti Fatimah Abdul Razak, Multimedia University, Ayer Keroh, Malaysia

The applicability of V2V or V2I (V2X) has been added in Table 2 (page 7).

The comparative analysis has been highlighted in Table 3 (page 7).

The conclusion has been revised as suggested (page 9).

Competing Interests: No competing interests were disclosed.

Reviewer Report 19 July 2022

https://doi.org/10.5256/f1000research.77046.r143137

(C) 2022 Nkenyereye L. This is an open access peer review report distributed under the terms of the Creative Commons Attribution License, which permits unrestricted use, distribution, and reproduction in any medium, provided the original work is properly cited.

\section{Lionel Nkenyereye}

Department of Computer and Information Security, Sejong University, Seoul, South Korea

The study surveys the existing simulation framework for connected vehicles. The works proposed a method based on PRISMA Extension for a Scoping Review. The previous study table is short but relevant contributions are presented. These contributions summarize the routing concept, dissemination of the information, and performance measures in terms of throughput and packet delivery ratio.

The following comments could enhance the quality of this work:

1. In the conclusion, I request the authors to specify the type of mobility generator and mobility network that are efficient for real-time system modelling.

2. At the Screening section, authors focus much on VANET. How about other vehicular network that support V2V? For instance software-defined based VANET or vehicular Edge/Fog technology or Vehicular Cloud network in their Search string. Is the current work includes different type of vehicular technology in general? Therefore, rewrite in the introduction that this study focuses particularly on VANET. 
Are the rationale for, and objectives of, the Systematic Review clearly stated? Yes

Are sufficient details of the methods and analysis provided to allow replication by others? Yes

Is the statistical analysis and its interpretation appropriate?

Yes

Are the conclusions drawn adequately supported by the results presented in the review? Partly

Competing Interests: No competing interests were disclosed.

Reviewer Expertise: Vehicular technology, edge computing, and software-defined networks I confirm that I have read this submission and believe that I have an appropriate level of expertise to confirm that it is of an acceptable scientific standard, however I have significant reservations, as outlined above.

\section{Author Response 26 Jan 2023}

Siti Fatimah Abdul Razak, Multimedia University, Ayer Keroh, Malaysia

The paper is mainly focusing on VANET deployment. The introduction has been revised as suggested (page 2 and 3).

The conclusion has been revised to specify the type of mobility generator and mobility network that are efficient for real-time system modelling (page 9).

Competing Interests: No competing interests were disclosed. 
The benefits of publishing with F1000Research:

- Your article is published within days, with no editorial bias

- You can publish traditional articles, null/negative results, case reports, data notes and more

- The peer review process is transparent and collaborative

- Your article is indexed in PubMed after passing peer review

- Dedicated customer support at every stage

For pre-submission enquiries, contact research@f1000.com 